\title{
Editor's Choice of Books Received (2012)
}

Fritz Allhoff, Terrorism, Ticking Time-Bombs, and Torture (Chicago: The University of Chicago Press, 2012), 266 pages.

John Martin Fischer, Deep Control (Oxford: Oxford University Press, 2012), 244 pages.

Annabelle Lever, On Privacy (London: Routledge, 2012), 100 pages.

T. M. Wilkinson, Ethics and the Acquisition of Organs (Oxford: Oxford University Press, 2011), 209 pages. 